\title{
EFFECTS OF A TANTALUM ADDITION ON THE MORPHOLOGICAL AND COMPOSITIONAL EVOLUTION OF A MODEL Ni-Al-Cr SUPERALLOY
}

\author{
Christopher Booth-Morrison ${ }^{1}$, Ronald D. Noebe ${ }^{2}$, David N. Seidman ${ }^{1,3}$ \\ ${ }^{1}$ Department of Materials Science and Engineering, Northwestern University; 2220 Campus Drive; Evanston, Illinois, 60208, USA \\ ${ }^{2}$ NASA Glenn Research Center; 21000 Brookpark Rd.; Cleveland, Ohio, 44135, USA \\ ${ }^{3}$ Northwestern University Center for Atom-Probe Tomography (NUCAPT); 2220 Campus Drive; Evanston, Illinois, 60208, USA
}

Keywords: Nickel-based superalloys; Tantalum; Atom-probe tomography; Nanostructures

\begin{abstract}
The effects of a 2.0 at. $\%$ addition of Ta to a model Ni-Al-Cr superalloy aged at $1073 \mathrm{~K}$ are assessed using scanning electron microscopy and atom-probe tomography. The addition of $\mathrm{Ta}$ results in appreciable strengthening, and the morphology is found to evolve from a bimodal distribution of spheroidal precipitates, to cuboidal precipitates aligned along the elastically soft $<001>$-type directions. Tantalum is observed to partition preferentially to the $\gamma$ '-precipitate phase and decreases the mobility of $\mathrm{Ni}$ in the $\gamma$ matrix sufficiently to cause an accumulation of $\mathrm{Ni}$ on the $\gamma$-matrix side of the $\gamma^{\prime}$-precipitate $/ \gamma$-matrix heterophase interface.
\end{abstract}

\section{Introduction}

The high-temperature properties of nickel-based superalloys allow these materials to be used in a wide range of applications at operating temperatures up to $1373 \mathrm{~K}$, in highly corrosive environments where other materials are unsuitable [1]. The ability of nickel-based superalloys to endure such severe environments is due in part to strengthening of the nickel-rich $\gamma$ (f.c.c.)-matrix solid-solution by both solute elements and precipitates.

Tantalum has played an important role in the development of complex concentrated multicomponent superalloys as both a solid-solution strengthener and a precipitate former [1-4]. The addition of $\mathrm{Ta}$ to superalloys increases the high-temperature strength and ductility, and the resistance to creep, fatigue, and corrosion, of these high-performance materials $[2,5]$. While the effects of Ta on the microstructure and mechanical properties of superalloys [5-10] have been studied, little work has been done to characterize the morphological and compositional changes due to the addition of Ta.

The work reported herein focuses on the temporal evolution of the nanostructural and compositional properties of a model Ni-Al-CrTa alloy that decomposes to form a microstructure consisting of $\gamma^{\prime}\left(\mathrm{Ll}_{2}\right)$-precipitates in a $\gamma($ f.c.c. $)$-matrix. The addition of $\mathrm{Cr}$ to the binary $\mathrm{Ni}-\mathrm{Al}$ system reduces the lattice parameter misfit between the $\gamma$ '-precipitates and the $\gamma$-matrix, allowing the $\gamma$ '-precipitates to remain spherical or spheroidal to fairly large dimensions as aging progresses [11]. The addition of Ta has been shown to provide significant strengthening by increasing the volume fraction of the $\gamma$-precipitate phase, while also decreasing the inter-diffusivity between phases, improving phase stability and service life $[2,3]$.
The effects of a 2.0 at.\% addition of Ta to a model Ni-Al-Cr superalloy aged at $1073 \mathrm{~K}$ are studied using primarily scanning electron microscopy (SEM) and atom-probe tomography (APT). The effects are assessed by studying changes in the microhardness, the $\gamma^{\prime}$-precipitate morphology, the phase compositions, the partitioning ratio of the constituent elements, and the concentration profiles across the $\gamma$ '-precipitate $/ \gamma$-matrix interface, as the alloy ages.

\section{Experimental}

\section{Alloy Preparation}

High-purity constituent elements were induction-melted under a partial pressure of Ar and chill cast into a $19 \mathrm{~mm}$ diameter copper mold to form a polycrystalline master ingot. Samples from the cast ingot then underwent a three-stage heat-treatment: (1) homogenization at $1573 \mathrm{~K}$ in the $\gamma$-phase field for $20 \mathrm{~h}$; (2) a vacancy anneal in the $\gamma$-phase field at $1503 \mathrm{~K}$ for 3 hours followed by a water quench; and (3) an aging anneal at $1073 \mathrm{~K}$ under flowing argon for times ranging from 0.25 to $256 \mathrm{~h}$. The samples were again water quenched, and microtip specimens and metallographic samples were prepared from each of the aged sections for study by APT and SEM.

The overall composition of the master ingot was determined by inductively coupled plasma (ICP) atomic-emission spectroscopy to be $80.01 \mathrm{Ni}-9.75 \mathrm{Al}-8.21 \mathrm{Cr}-2.02 \mathrm{Ta}$ at.\%, and, within experimental error, was indistinguishable from the targeted composition of Ni-10.0 Al-8.5 Cr-2.0 Ta at.\%. ICP chemical analysis was also used to determine the compositions of the $\gamma$ matrix and $\gamma$ '-precipitate phases of a sample aged at $1073 \mathrm{~K}$ for $256 \mathrm{~h}$ after phase extraction by anodic dissolution of the $\gamma$-matrix phase with a 1:1 aqueous solution of citric acid and ammonium nitrate at constant current density. The commercial software package Thermo-Calc [12] was used to estimate the values of the equilibrium $\gamma^{\prime}$-precipitate volume fraction, $\phi^{e q}$, and the equilibrium compositions of the $\gamma$-matrix, $C_{i}^{\gamma, e q}(\infty)$, and $\gamma^{\prime}$ precipitate phases, $C_{i}^{\gamma^{\prime}, e q}(\infty)$, for each solute species $i$, using a database for nickel-based superalloys developed by Saunders [13], at a pressure of 1 atmosphere. The tracer diffusivities of the atomic species in the $\gamma$-matrix phase were calculated employing Dictra [14] with the mobility database due to Campbell [15] and employing the Saunders thermodynamic database. 
$\underline{\text { Experimental Procedures }}$

Vickers microhardness was measured using a Buehler Micromet $^{\mathrm{TM}}$ at a load of $500 \mathrm{~g}$, sustained for $5 \mathrm{~s}$, on mounted samples polished to $1 \mu \mathrm{m}$, using the average value of fifteen independent measurements made on several grains. SEM was performed on mounted samples polished to a $0.02 \mu \mathrm{m}$ finish and etched in a $100 \mathrm{ml} \mathrm{HCl} / 100 \mathrm{ml}$ deionized $\mathrm{H}_{2} \mathrm{O} / 1 \mathrm{~g} \mathrm{~K}_{2} \mathrm{~S}_{2} 0_{5}$ mixture, employing a LEO Gemini $1525^{\mathrm{TM}}$ field-emission SEM operated at $5 \mathrm{kV}$ with a 20-30 $\mu \mathrm{m}$ aperture and a working distance of $6 \mathrm{~mm}$. APT was performed with a local-electrode atom-probe (LEAPTM) tomograph [16-19] at the Northwestern University Center for Atom-Probe Tomography (NUCAPT). Pulsed-laser APT data collection was performed at a target evaporation rate of 0.04 ions per pulse, a specimen temperature of $40.0 \pm 0.3 \mathrm{~K}$, a pulse energy of $0.6 \mathrm{~nJ}$, a pulse repetition rate of $200 \mathrm{kHz}$, and a background gauge pressure of $<6.7 \times 10^{-8} \mathrm{~Pa}$. APT data were analyzed with the IVAS ${ }^{\circledR} 3.0$ software program (Imago Scientific Instruments, Madison, Wisconsin). The $\gamma$ '-precipitate $/ \gamma$-matrix heterophase interfaces were delineated with $\mathrm{Al}$ isoconcentration surfaces generated by efficient sampling procedures [20]. Detailed compositional information was obtained with the proximity histogram method [21], and extrapolated to infinite time employing the predictions of classical coarsening models [22].

\section{Results}

\section{Equilibrium Volume Fraction and Phase Composition}

The values of $\phi^{e q}$ estimated by APT and Thermo-Calc for a Ni$10.0 \mathrm{Al}-8.5 \mathrm{Cr}-2.0 \mathrm{Ta}$ at.\% alloy aged at $1073 \mathrm{~K}$ are presented in Table I, and compared to the values of the precipitated volume fraction, $\phi$, at $256 \mathrm{~h}$, as measured by both APT and ICP chemical analysis. The values of $\phi$ estimated by APT at $256 \mathrm{~h}$ are within experimental error of the values of $\phi^{e q}$, suggesting that growth of the $\gamma^{\prime}$-precipitate phase is complete and that the alloy may be undergoing quasi-stationary-state coarsening. A pure coarsening regime can occur only when an equilibrium value of $\phi$ is achieved and the supersaturations are zero.

Table I. Equilibrium $\gamma^{\prime}$-precipitate volume fraction, $\phi^{e q}$, determined by APT, ICP chemical analysis, and thermodynamic modeling employing Thermo-Calc for Ni-10.0 Al-8.5 Cr-2.0 Ta at.\% aged at $1073 \mathrm{~K}$.

\begin{tabular}{|l|c|}
\hline Technique used to estimate $\phi^{e q}:$ & $\phi^{e q}(\%)$ \\
\hline $\begin{array}{l}\text { Lever rule with APT compositions, } 256 \mathrm{~h}: \\
\text { Lever rule with equilibrium compositions } \\
\text { extrapolated from APT data: }\end{array}$ & $37.2 \pm 8.9$ \\
ICP chemical analysis, $256 \mathrm{~h}:$ & $37.0 \pm 9.0$ \\
Thermo-Calc and Saunders database [13]: & 38.17 \\
\hline
\end{tabular}

The values of $C_{i}^{\gamma^{\prime}, e q}(\infty)$ and $C_{i}^{\gamma, e q}(\infty)$ are listed in Table II. A comparison of these values to the compositions measured by APT and ICP analysis after $256 \mathrm{~h}$ of aging shows that the phase compositions are near their equilibrium values at $256 \mathrm{~h}$. Thus, the $\gamma$-matrix supersaturations are small and $\gamma$ '-precipitate growth is nearly complete, and the alloy may be undergoing quasistationary-state coarsening.
Table II. Equilibrium $\gamma^{\prime}$-precipitate, $C_{i}^{\gamma^{\prime}, e q}(\infty)$, and $\gamma$ matrix, $C_{i}^{\gamma, e q}(\infty)$, compositions determined by APT, ICP analysis, and Thermo-Calc for Ni-10.0 Al-8.5 Cr2.0 Ta at. $\%$ aged at $1073 \mathrm{~K}$ (at.\%).

\begin{tabular}{|l|cccc|}
\hline Technique: & $C_{N i}^{\gamma^{\prime}, e q}(\infty)$ & $C_{A l}^{\gamma^{\prime}, e q}(\infty)$ & $C_{C r}^{\gamma^{\prime}, e q}(\infty)$ & $C_{T a}^{\gamma^{\prime}, e q}(\infty)$ \\
& & & & \\
\hline \multirow{2}{*}{ APT, 256 h: } & 75.37 & 16.56 & 3.25 & 4.82 \\
& \pm 0.05 & \pm 0.08 & \pm 0.09 & \pm 0.09 \\
APT: & 75.24 & 16.48 & 3.20 & 5.03 \\
& \pm 0.08 & \pm 0.07 & \pm 0.06 & \pm 0.07 \\
ICP, 256 h: & 75.56 & 16.57 & 3.28 & 4.58 \\
& & & & \\
Thermo-Calc: & 76.47 & 17.00 & 2.66 & 3.88 \\
\hline & & & & \\
Technique: & $C_{N i}^{\gamma, e q}(\infty)$ & $C_{A l}^{\gamma, e q}(\infty)$ & $C_{C r}^{\gamma, e q}(\infty)$ & $C_{T a}^{\gamma, e q}(\infty)$ \\
& & & & \\
\hline \multirow{2}{*}{ APT, 256 h: } & 81.65 & 5.23 & 12.66 & 0.47 \\
& \pm 0.01 & \pm 0.03 & \pm 0.03 & \pm 0.03 \\
APT: & 81.68 & 5.18 & 12.70 & 0.44 \\
& \pm 0.04 & \pm 0.08 & \pm 0.02 & \pm 0.06 \\
ICP, 256 h: & 83.17 & 5.49 & 10.74 & 0.60 \\
Thermo-Calc: & 81.37 & 5.68 & 12.11 & 0.84 \\
\hline
\end{tabular}

\section{Microhardness Testing}

The microhardness of Ni-10.0 Al-8.5 $\mathrm{Cr}-2.0 \mathrm{Ta}$ at.\%, aged at $1073 \mathrm{~K}$ for $t=0-256 \mathrm{~h}$, Figure 1, varies from 3.3 to $3.6 \mathrm{GPa}$, with peak microhardness occurring between $t=1$ and $16 \mathrm{~h}$. For Ni-10.0 Al-8.5 Cr at.\% aged at $1073 \mathrm{~K}$, the microhardness varies over a narrow range, $2.15 \mathrm{GPa}$ to $2.5 \mathrm{GPa}$, with peak microhardness occurring at $4 \mathrm{~h}[23,24]$. The addition of 2.0 at.\% Ta therefore results in an increase in microhardness of $47 \pm 5 \%$ over the range of aging times studied.

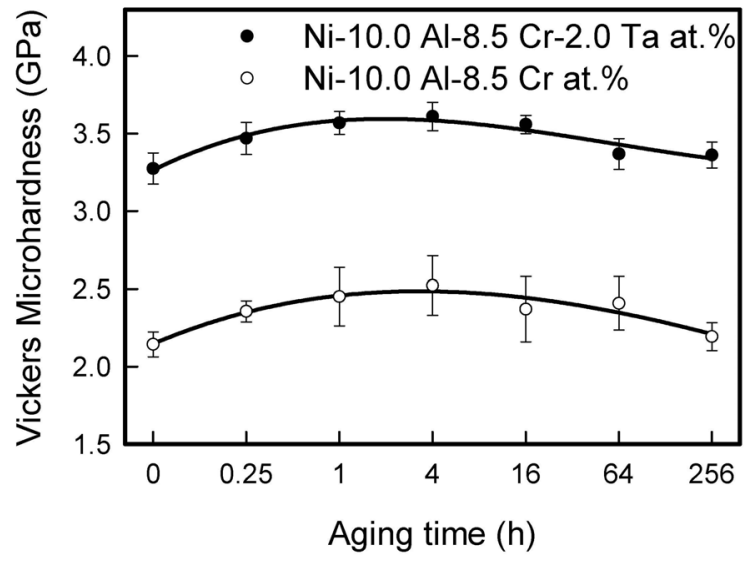

Figure 1. Vickers microhardness measurements for Ni10.0 Al-8.5 Cr-2.0 Ta and Ni-10.0 Al-8.5 Cr at.\% aged at $1073 \mathrm{~K}$. 


\section{Morphological Development}

The morphology of the Ni-Al-Cr-Ta alloy evolves from a bimodal distribution of spheroidal $\gamma$ '-precipitates, to cuboids with significantly rounded edges, and finally to a cuboidal morphology with $\gamma$ '-precipitates aligned along the elastically soft $<001>$-type directions, Figures 2 and 3.
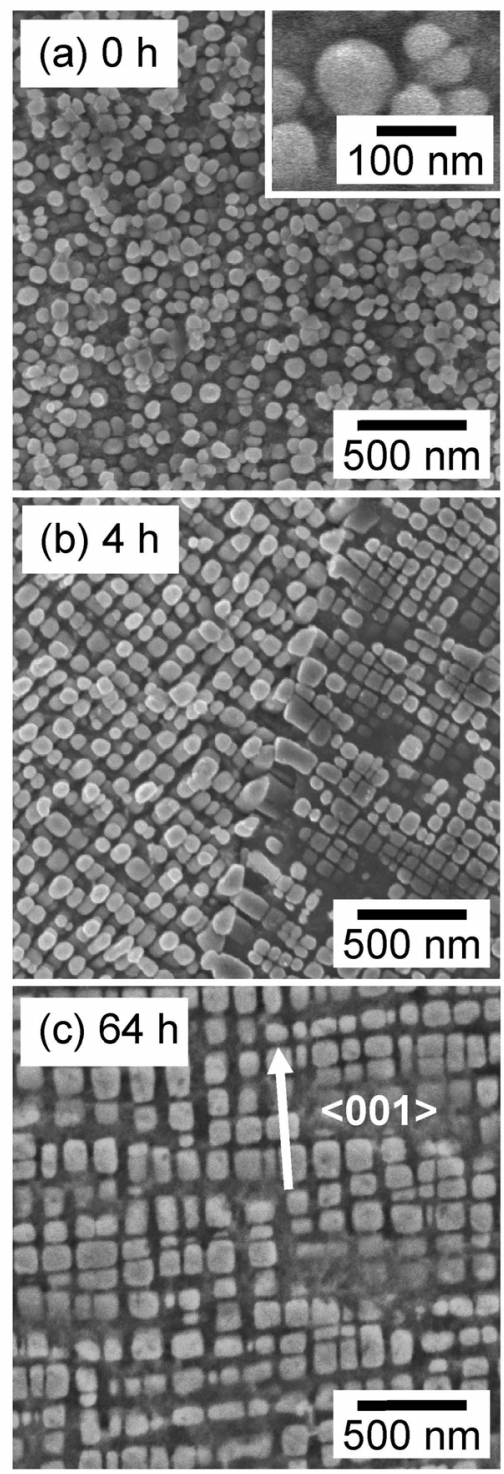

Figure 2. SEM images of a Ni-10.0 Al-8.5 Cr-2.0 Ta at.\% alloy aged at $1073 \mathrm{~K}$ for: (a) $0 \mathrm{~h}$; (b) $4 \mathrm{~h}$; and (c) $64 \mathrm{~h}$. The $\gamma^{\prime}$-precipitate morphology evolves from spheroidal $\gamma$ '-precipitates to a cuboidal morphology with $\gamma$-precipitates aligned along the elastically soft $<001>$-type directions.

In the as-quenched state, a bimodal distribution of $\gamma^{\prime}$-precipitates is observed, Figure 3a, consisting of larger primary $\gamma$ '-precipitates with radii, $R$, on the order of 30-40 nm and smaller secondary $\gamma^{\prime}-$ precipitates with radii of 3-5 $\mathrm{nm}$. The smaller $\gamma^{\prime}$-precipitates are lost during the etching process and are not detected in SEM micrographs, Figure $2 \mathrm{a}$. For aging times beyond the as-quenched state, the $\gamma^{\prime}$-precipitates begin to adopt a $\{100\}$-faceted cuboidal morphology with rounded corners, as can be seen by both SEM, Figure 2b, and APT, Figure 3b, for a sample aged for $4 \mathrm{~h}$. Figure $2 \mathrm{~b}$ shows $\gamma^{\prime}$-precipitates that have nucleated and grown heterogeneously at a grain boundary. The cuboidal morphology of the $\gamma$ '-precipitates persists with longer aging, and for aging times of $4 \mathrm{~h}$ and longer, the $\gamma^{\prime}$-precipitates align along orthogonal $<001>$-type directions, Figures $2 \mathrm{c}$ and $3 \mathrm{c}$.
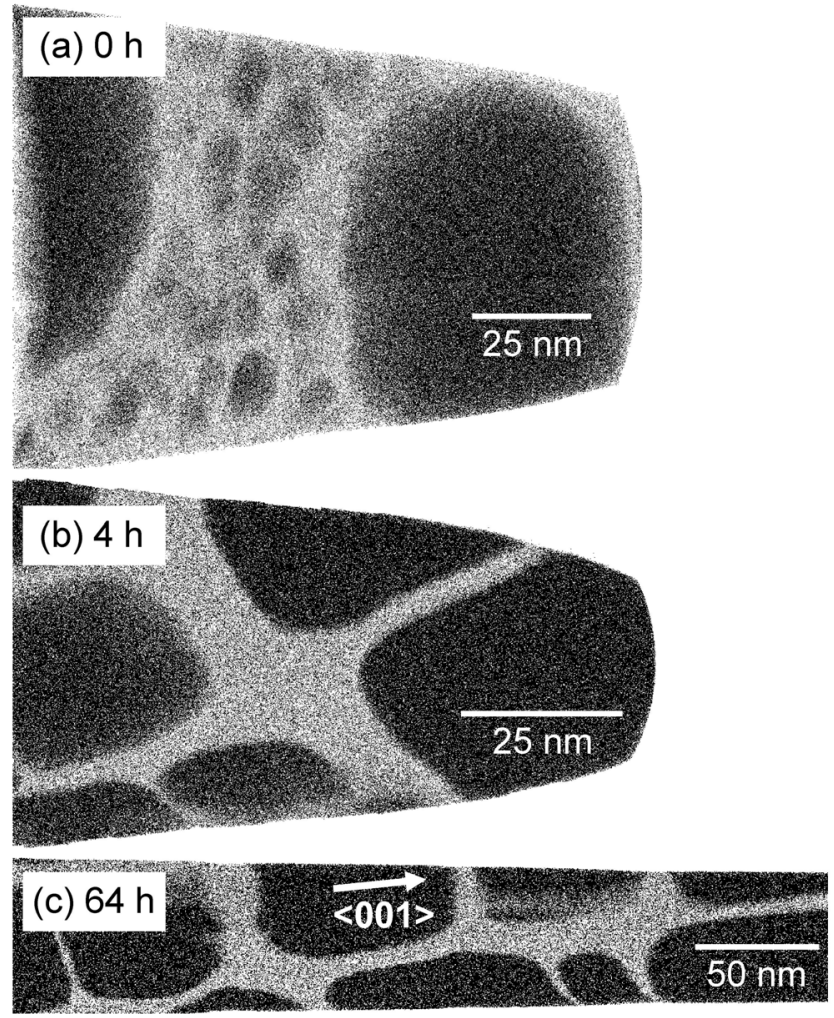

Figure 3. APT images of a Ni-10.0 Al-8.5 Cr-2.0 Ta at.\% alloy aged at $1073 \mathrm{~K}$ for: (a) $0 \mathrm{~h}$; (b) $4 \mathrm{~h}$; and (c) $64 \mathrm{~h}$. The elements that partition to the $\gamma$ '-precipitates, $\mathrm{Ta}$ and $\mathrm{Al}$, are shown in black, while $\mathrm{Cr}$, which partitions to the $\gamma$-matrix, is shown in white; $\mathrm{Ni}$ atoms are omitted for clarity. The morphology of the $\gamma^{\prime}-$ precipitate phase is spheroidal in the as-quenched state, and a bimodal particle size distribution is apparent. The smaller $\gamma$ '-precipitates are observed to have radii of 3-5 nm, while the larger $\gamma$ '-precipitates have radii on the order of 30-40 nm. After aging for $64 \mathrm{~h}$, the $\gamma^{\prime}-$ precipitates are distinctly cuboidal and aligned crystallographically.

Temporal Evolution of the Concentration Profiles at the $\gamma^{\prime}$ precipitate $/ \gamma$-matrix Interface

The compositional information generated by APT permits the study of both the temporal evolution of the phase compositions, and of the concentration profiles at the $\gamma^{\prime}$-precipitate $/ \gamma$-matrix interface, Figure 4. The phase compositions evolve temporally, and an accumulation of $\mathrm{Ni}$, and a depletion of $\mathrm{Cr}$, is observed approximately $2 \mathrm{~nm}$ into the $\gamma$-matrix. This effect was not detected 
for Ni-10.0 Al-8.5 $\mathrm{Cr}$ at.\% [23, 24], and is likely a kinetic effect associated with the addition of Ta.

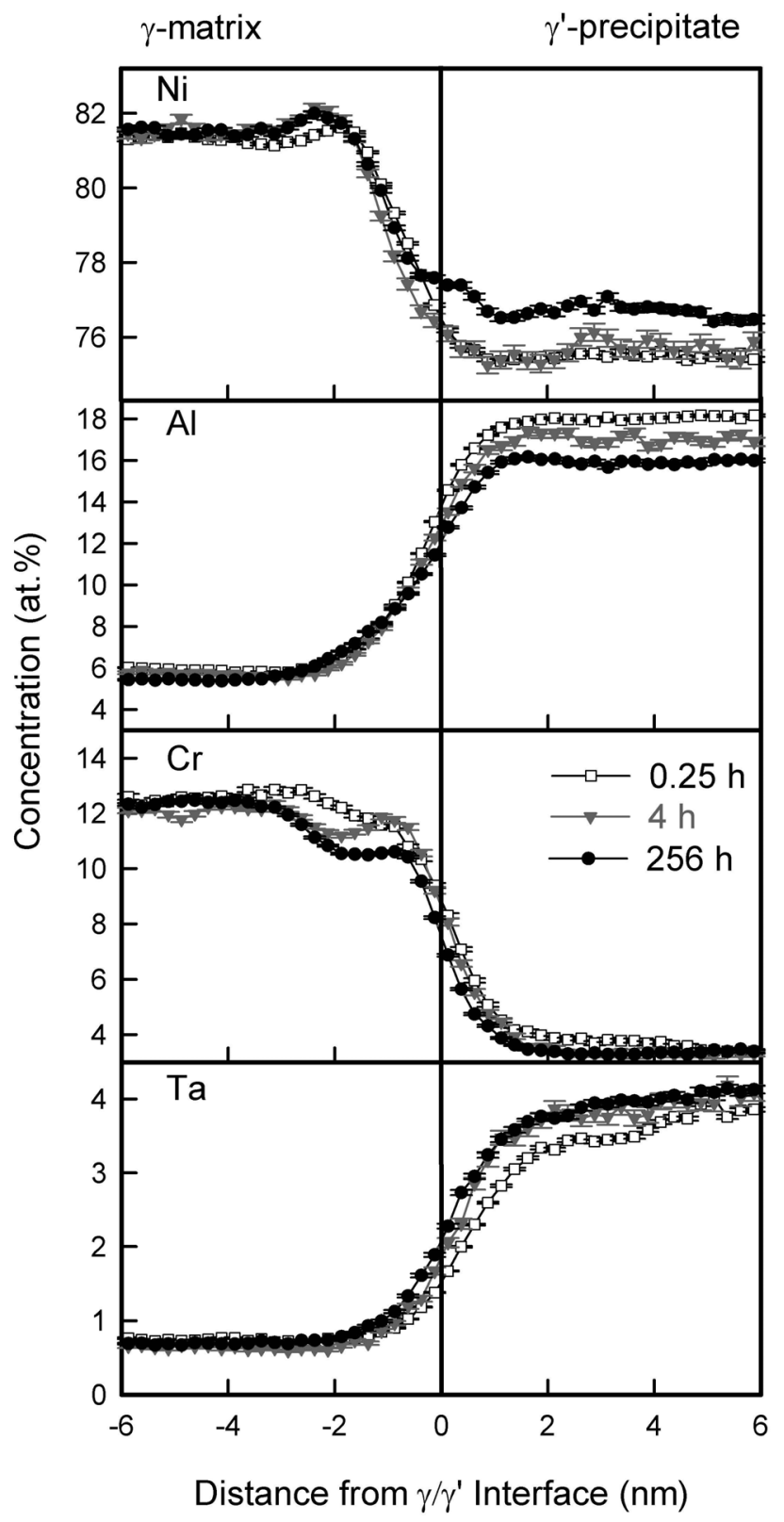

Figure 4. The concentration profiles of the constituent elements across the $\gamma$ '-precipitate/ $\gamma$-matrix heterophase interface for a Ni-10.0 Al-8.5 Cr-2.0 Ta at.\% alloy aged at $1073 \mathrm{~K}$. The phase compositions evolve temporally, and the widths of the interfaces decrease with increasing aging time. An accumulation of $\mathrm{Ni}$ is observed to develop on the $\gamma$-matrix side of the heterophase interface, evidence of a kinetic effect associated with the addition of Ta.

\section{Partitioning of Elemental Species}

The partitioning behavior of the elements can be determined quantitatively by calculating the partitioning ratio, $K_{i}^{\gamma^{\prime} / \gamma}$, the ratio of the concentration of an element $i$ in the $\gamma^{\prime}$-precipitates to the concentration of the same element in the $\gamma$-matrix, Figure 5. Aluminum and Ta are observed to partition to the $\gamma$ '-precipitates, while $\mathrm{Cr}$ and $\mathrm{Ni}$ partition to the $\gamma$-matrix. The strong partitioning of Ta to the $\gamma^{\prime}$-precipitates reduces the partitioning of Al to the $\gamma^{\prime}$ phase, and increases the partitioning of $\mathrm{Cr}$ to the $\gamma$-matrix, when compared to the results obtained for a ternary Ni-10.0 Al-8.5 Cr at.\% alloy [23, 24], Figure 5; the partitioning of $\mathrm{Ni}$ is unaffected by the addition of Ta.

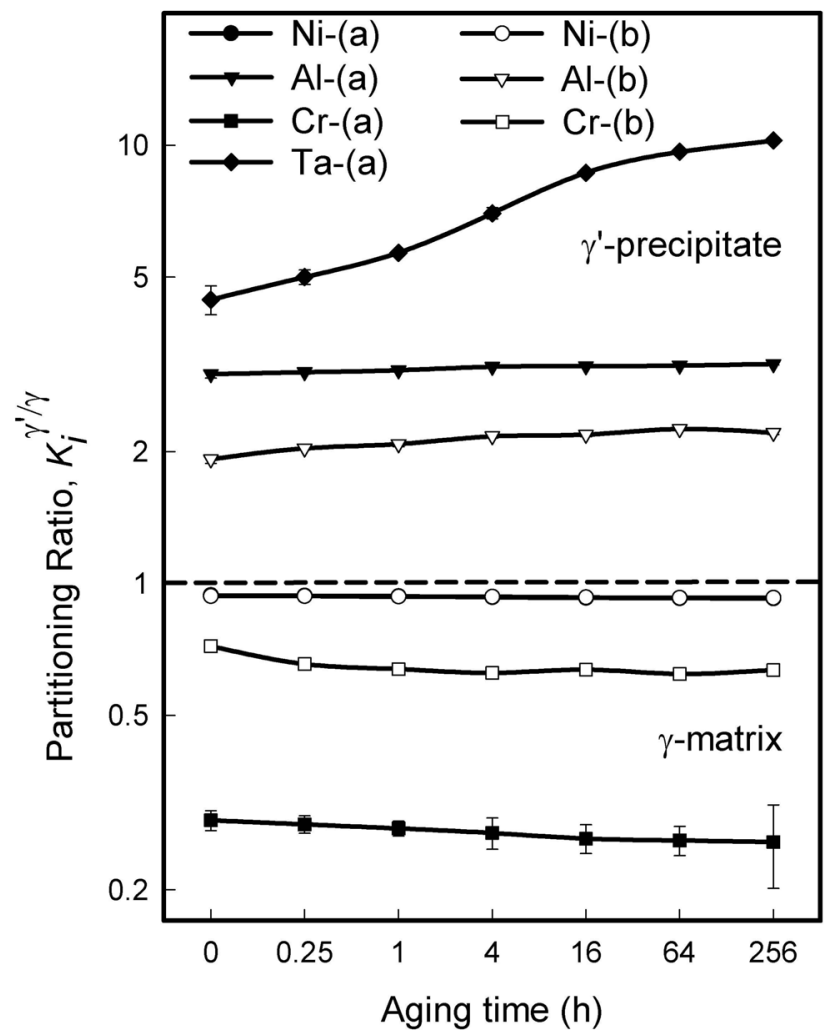

Figure 5. The temporal evolution of the partitioning ratios, $K_{i}^{\gamma^{\prime} / \gamma}$, of the constituent elements $i$ of: (a) $\mathrm{Ni}$ 10.0 Al-8.5 Cr-2.0 Ta; and (b) Ni-10.0 Al-8.5 Cr at.\% aged at $1073 \mathrm{~K}$. Aluminum and $\mathrm{Ta}$ are observed to partition to the $\gamma$ '-precipitates, while $\mathrm{Cr}$ and $\mathrm{Ni}$ partition to the $\gamma$-matrix. For all aging times, the $K_{N i}^{\gamma^{\prime} / \gamma}$ values of the two alloys are identical, within experimental error.

\section{Discussion}

The addition of 2.0 at. $\%$ Ta to a model Ni-Al-Cr system results in a dramatic increase in the value of $\phi^{e q}$ from $18.9 \%$ for a ternary $\mathrm{Ni}-10.0 \mathrm{Al}-8.5 \mathrm{Cr}$ at.\% alloy $[23,24]$ to $37.0 \pm 9.0 \%$ for the quaternary alloy when aged at $1073 \mathrm{~K}$. The added solid-solution strengthening provided by Ta, and the increase in the value of $\phi^{e q}$, lead to an increase in microhardness of $47 \pm 5 \%$ over the full range of aging times. A similar increase in microhardness of $41 \pm 9 \%$ was previously observed for a 2.0 at. $\% \mathrm{~W}$ addition to Ni-10.0 Al$8.5 \mathrm{Cr}$ at.\%, which resulted in a $\phi^{e q}$ value of $30.8 \%[23,24]$. 


\section{Morphological Development}

The morphology of the $\gamma^{\prime}$-precipitates is observed to evolve from a bimodal distribution of spheroidal $\gamma$ '-precipitates to cuboids with significantly rounded edges, and finally to cuboids aligned along orthogonal $<001>$-type directions. The $\gamma^{\prime}$-precipitates that form the original bimodal distribution in the as-quenched state nucleate rapidly during the quench due to the low barrier to nucleation and the large supersaturations of alloying elements. The larger $\gamma$ '-precipitates nucleate first, but with additional cooling, a supersaturation of solute develops in the interprecipitate spaces, resulting in the secondary burst of smaller precipitates observed between the larger $\gamma$ '-precipitates, Figure $3 \mathrm{a}$.

The evolution of the spheroidal $\gamma$ '-precipitates into cuboids in the $\mathrm{Ni}-\mathrm{Al}-\mathrm{Cr}-\mathrm{Ta}$ alloy commences at an aging time of $0.25 \mathrm{~h}$, when the $\gamma$ '-precipitates have an average radius of $30-50 \mathrm{~nm}$. The radius at which the microstructure becomes cuboidal for the base Ni-Al$\mathrm{Cr}$ alloy was estimated to be $\sim 88 \mathrm{~nm}$, and occurred at an aging time of $64 \mathrm{~h}[23,24]$ at $1073 \mathrm{~K}$. The spheroid-to-cuboid transition is determined by a competition of the elastic self-energy and the $\gamma^{\prime}$-precipitate/ $\gamma$-matrix heterophase interfacial free energy [25]. The elastic self-energy of a precipitate increases as $R^{3}$, while the interfacial free energy increases as $R^{2}$. Thus as coarsening proceeds, and the average precipitate radius increases in elastically-stressed alloy systems such as the one studied here, the elastic energy ultimately determines the precipitate morphology, and is decreased by the formation of cuboidal $\gamma$ '-precipitates.

The $\gamma$ '-precipitates of a Ni-10.0 Al-8.5 Cr-2.0 W at.\% alloy were previously observed to become cuboidal at an aging time of $32 \mathrm{~h}$, when the precipitates have an average radius of $\sim 50 \mathrm{~nm}[23,24]$. For the case of the Ni-Al-Cr-W alloy, it was reasoned that the transition from spheroids to cuboids occurs at a smaller radius than for the model $\mathrm{Ni}-\mathrm{Al}-\mathrm{Cr}$ alloy because of a larger lattice parameter misfit between the $\gamma^{\prime}$-precipitate and $\gamma$-matrix phases in the Ni-Al-Cr-W system. The same logic applies to the Ni-Al-CrTa system; a calculation of the lattice parameters based on Vegard's law and the partitioning of solute elements [1], reveals that the lattice parameter misfit increases by $110 \%$, from $0.59 \%$ to $1.25 \%$, due to the addition of 2.0 at.\% Ta. The alignment of the $\gamma$ '-precipitates as aging progresses results from the minimization of the elastic interactions between the $\gamma^{\prime}$-precipitates, where the interaction energy depends on the elastic anisotropy, the difference in the elastic constants of the two phases, and the sign and magnitude of the misfit strain $[26,27]$.

\section{$\underline{\text { Compositional Evolution }}$}

The APT results show strong partitioning of Al and Ta to the $\gamma$ 'precipitate phase, while $\mathrm{Ni}$ and $\mathrm{Cr}$ partition to the $\gamma$-matrix phase, in agreement with prior experimental work [5, 9, 10, 28-31]. The experimentally determined equilibrium composition of the $\gamma^{\prime}$ precipitate phase of $75.24 \mathrm{Ni}-16.48 \mathrm{Al}-3.20 \mathrm{Cr}-5.03 \mathrm{Ta}$ at.\% suggests that $\mathrm{Al}, \mathrm{Ta}$ and $\mathrm{Cr}$ occupy the $\mathrm{Al}$ sites of the $\mathrm{L1}_{2}$-ordered $\mathrm{Ni}_{3} \mathrm{Al}$-type $\gamma^{\prime}$-precipitate phase of the Ni-Al-Cr-Ta alloy at 1073 K. Previous APT, atom probe field-ion microscope (APFIM) [30, $32,33]$, x-ray analysis $[34,35]$, and diffusion couple technique [31] experiments, as well as results of Monte Carlo simulations [36] and calculations employing first-principles [37-40], the cluster variation method [41-44], and other techniques [45, 46], have shown that Ta occupies the $\mathrm{Al}$ sites in the ordered $\mathrm{Ni}_{3} \mathrm{Al}$ structure. These results contradict experimental results from ion channeling and nuclear reaction studies [47] and results based on short-range ordering parameters determined from pseudopotential approximations [48], which conclude that Ta occupies the Ni sites in the $\mathrm{Ni}_{3} \mathrm{Al}$ structure. Chromium has been found to occupy both the $\mathrm{Ni}$ or $\mathrm{Al}$ sites, depending on the composition of the alloy studied [34, 36, 37, 39, 43, 48, 49].

The most striking feature of the concentration profiles across the $\gamma^{\prime}$-precipitate/ $\gamma$-matrix heterophase interface, Figure 4 , is the accumulation of $\mathrm{Ni}$ in the $\gamma$-matrix, roughly $2 \mathrm{~nm}$ from the interface. This effect is likely kinetic in origin, resulting from a decrease in the diffusivity of $\mathrm{Ni}$ in the $\gamma$-matrix, as evidenced by a threefold decrease in the calculated $\gamma$-matrix tracer diffusivity of $\mathrm{Ni}, D_{N i}^{\gamma}$, from $6.06 \times 10^{-18} \mathrm{~m}^{2} \mathrm{~s}^{-1}$ to $2.02 \times 10^{-18} \mathrm{~m}^{2} \mathrm{~s}^{-1}$ due to a 2.0 at.\% addition of Ta, Table III. This effect is significant because Ni becomes the least mobile species in the $\gamma$-matrix. As $\mathrm{Ni}$ partitions to the $\gamma$-matrix during phase decomposition, the diffusivity of $\mathrm{Ni}$ is not sufficient to transport all of the $\mathrm{Ni}$ atoms away from the interface and an accumulation of $\mathrm{Ni}$ is observed. The diffusivities of the other atomic species do not decrease by more than $10 \%$ with the addition of Ta, though a decrease in the coarsening kinetics is anticipated.

Table III. Tracer diffusivity, $D_{i}^{\gamma}$, of element $i$ in the $\gamma$ matrix of Ni-10.0 Al-8.5 Cr and Ni-10.0 Al-8.5 Cr-2.0 Ta at.\% calculated with Dictra at $1073 \mathrm{~K}\left(10^{-18} \mathrm{~m}^{2} \mathrm{~s}^{-1}\right)$ :

\begin{tabular}{|c|cccc|}
\hline Alloy (at.\%) & $D_{N i}^{\gamma}$ & $D_{A l}^{\gamma}$ & $D_{C r}^{\gamma}$ & $D_{T a}^{\gamma}$ \\
\hline $\begin{array}{c}\text { Ni-10.0 Al- } \\
8.5 \mathrm{Cr}\end{array}$ & 6.06 & 13.9 & 5.13 & - \\
$\begin{array}{c}\text { Ni-10.0 Al- } \\
8.5 \mathrm{Cr}-2.0 \mathrm{Ta}\end{array}$ & 2.02 & 12.6 & 4.80 & 5.14 \\
\hline
\end{tabular}

\section{Summary and Conclusions}

The effect of a 2.0 at.\% Ta addition to a model Ni-Al-Cr superalloy aged at $1073 \mathrm{~K}$ for 0 to $256 \mathrm{~h}$ is assessed using scanning electron microscopy and atom-probe tomography, leading to the following conclusions:

- The addition of Ta results in a $47 \pm 5 \%$ increase in microhardness, due to increases in solid-solution strengthening and in the precipitated volume fraction.

- The morphology is found to evolve from a bimodal distribution of spheroidal precipitates, to cuboids with significantly rounded edges, and finally to cuboidal precipitates aligned along the elastically soft $<001>$-type directions. The transition from a spheroidal to a cuboidal morphology commences at an aging time of $0.25 \mathrm{~h}$, when the primary $\gamma^{\prime}$-precipitates have radii of $30-50 \mathrm{~nm}$.

- Aluminum and Ta partition to the $\gamma^{\prime}$-precipitates, while $\mathrm{Cr}$ and Ni partition to the $\gamma$-matrix. The strong partitioning of Ta to the $\gamma$-precipitates decreases the partitioning of Al to the $\gamma$ '-precipitates, and increases the partitioning of $\mathrm{Cr}$ to the $\gamma$-matrix, when compared to the results obtained for the base $\mathrm{Ni}-\mathrm{Al}-\mathrm{Cr}$ alloy aged at $1073 \mathrm{~K}[23,24]$.

- The concentration profiles of the constituent elements of the model Ni-Al-Cr-Ta alloy across the $\gamma$ '-precipitate $/ \gamma$-matrix interface exhibit an accumulation of $\mathrm{Ni}$ on the $\gamma$-matrix side of the interface. This effect is likely due to the diminution of the mobility of $\mathrm{Ni}$ in the $\gamma$-matrix due to the addition of $\mathrm{Ta}$. 


\section{Acknowledgements}

This research was sponsored by the National Science Foundation (NSF) under grant DMR-0241928. The SEM work was performed in the NUANCE Center at Northwestern University, which is supported by NSF-NSEC, NSF-MRSEC, the Keck Foundation, the State of Illinois, and Northwestern University. APT measurements were performed at the Northwestern University Center for Atom Probe Tomography (NUCAPT). The LEAP tomograph was purchased with funding from the NSF-MRI (DMR 0420532, Dr. C. Bouldin, grant officer) and ONR-DURIP (N00014-0400798, Dr. J. Christodoulou, grant officer) programs, and enhanced with a picosecond laser with funding from the ONR-DURIP (N00014-0610539, Dr. J. Christodoulou, grant officer). We extend our gratitude to Dr. C. Campbell for diffusivity calculations, to Mr. M. Anderson for SEM work, to Dr. C. Sudbrack and Dr. K. Yoon for discussions, and to Research Prof. D. Isheim for managing NUCAPT.

\section{References}

1. Reed, R. C., The Superalloys: Fundamentals and Applications (Cambridge University Press, New York, 2006), 372.

2. Jena, A. K. and Chaturvedi, M. C., "The Role of Alloying Elements in the Design of Nickel-Base Superalloys," J. Mater. Sci., 19 (10) (1984), 3121-3139.

3. Forde, P. T., "Tantalum in Superalloys," Adv. Mater. Processes, 149 (4) (1996), 39-40.

4. Kumar, P., Role of Niobium and Tantalum in Superalloys. in Advances in High Temperature Structural Materials and Protective Coatings, ed. Koul, A. K., Parameswaran, V. R., Immarigeon, J.-P. and Wallace, W. National Research Council of Canada, Ontario (Canada), 1994.

5. Meng, Z., Sun, G., Li, M. and Xie, X., "The Strengthening Effect of Tantalum in Nickel-Base Superalloys," Proc. Int. Symp. Super., (1984), 563-572.

6. Kear, B. H. and Pope, D. P., "Role of Refractory Elements in Strengthening of $\gamma^{\prime}$ and $\gamma^{\prime}$ Precipitation Hardened Nickel-Base Superalloys," Proc. Int. Symp. Super., (1984), 135-151.

7. Nathal, M. V. and Ebert, L. J., "The Influence of Cobalt, Tantalum, and Tungsten on the Elevated Temperature Mechanical Properties of Single Crystal Nickel-Base Superalloys," Metall. Trans. A, 16A (10) (1985), 1863-1870.

8. Brinegar, J. R., Mihalisin, J. R. and VanderSluis, J., "The Effects of Tantalum for Niobium Substitutions in Alloy 713C," Proc. Int. Symp. Super., (1984), 53-62.

9. Nathal, M. V. and Ebert, L. J., "The Influence of Cobalt, Tantalum, and Tungsten on the Microstructure of Single Crystal Nickel-Base Superalloys," Metall. Trans. A, 16A (10) (1985), 1849-1862.

10. Janowski, G. M., Heckel, R. W. and Pletka, B. J., "The Effects of Tantalum on the Microstructure of two Polycrystalline Nickel-
Base Superalloys: B-1900 + Hf and MAR-M247," Metall. Trans. $A, 17$ A (11) (1986), 1891-1905.

11. Hornbogen, E. and Roth, M., "Distribution of Coherent Particles in Nickel Alloys.," Z. Metall., 58 (12) (1967), 842-855.

12. Sundman, B., Jansson, B. and Andersson, J. O., "The ThermoCalc databank system.," CALPHAD: Computer Coupling of Phase Diagrams and Thermochemistry, 9 (2) (1985), 153-190.

13. Saunders, N., "Phase Diagram Calculations for Ni-based Superalloys,” Proc. Int. Symp. Super., (1996), 101-110.

14. Borgenstam, A., Engstrom, A., Hoglund, L. and Agren, J., "DICTRA, a Tool for Simulation of Diffusional Transformations in Alloys," J. Phase Equilib., 21 (3) (2000), 269-280.

15. Campbell, C. E., Boettinger, W. J. and Kattner, U. R., "Development of a Diffusion Mobility Database for Ni-base Superalloys," Acta Mat., 50 (4) (2002), 775-792.

16. Bajikar, S. S., Larson, D. J., Kelly, T. F. and Camus, P. P., "Magnification and Mass Resolution in Local-Electrode Atom Probes.," Ultramicroscopy, 65 (1-2) (1996), 119-129.

17. Kelly, T. F., Camus, P. P., Larson, D. J., Holzman, L. M. and Bajikar, S. S., "On the Many Advantages of Local-Electrode Atom Probes. ," Ultramicroscopy, 62 (1-2) (1996), 29-42.

18. Seidman, D. N., "Three-Dimensional Atom-Probe Tomography: Advances and Applications," Annu. Rev. Mater. Res., 37 (2007), 127-158.

19. Kelly, T. F. and Miller, M. K., "Invited Review Article: Atom Probe Tomography," Rev. Sci. Instrum., 78 (3) (2007), 031101/031101-031101/031120.

20. Hellman, O. C., Blatz du Rivage, J. and Seidman, D. N., "Efficient Sampling for Three-dimensional Atom Probe Microscopy Data," Ultramicroscopy, 95 (2003), 199-205.

21. Hellman, O. C., Vandenbroucke, J. A., Rusing, J., Isheim, D. and Seidman, D. N., "Analysis of Three-Dimensional Atom-Probe Data by the Proximity Histogram," Microsc. Microanal., 6 (5) (2000), 437-444.

22. Yoon, K. E., Noebe, R. D. and Seidman, D. N., "Effects of Rhenium Addition on the Temporal Evolution of the Nanostructure and Chemistry of a Model Ni-Cr-Al Superalloy. II: Analysis of the Coarsening Behavior," Acta Mat., 55 (2007), 1159-1169.

23. Sudbrack, C. K., Isheim, D., Noebe, R. D., Jacobson, N. S. and Seidman, D. N., "The Influence of Tungsten on the Chemical Composition of a Temporally Evolving Nanostructure of a Model Ni-Al-Cr Superalloy," Microsc. Microanal., 10 (3) (2004), 355365 .

24. Sudbrack, C. K., Ziebell, T. D., Noebe, R. D. and Seidman, D. N., "Effects of a Tungsten Addition on the Morphological 
Evolution, Spatial Correlations, and Temporal Evolution of a Model Ni-Al-Cr Superalloy," Acta Mat., 56 (2008), 448-463.

25. Johnson, W. C. and Cahn, J. W., "Elastically Induced Shape Bifurcations of Inclusions," Acta Metall., 32 (11) (1984), 19251933.

26. Ardell, A. J. and Nicholson, R. B., "The Modulated Structure of Aged Nickel-Aluminum Alloys," Acta Metall., 14 (3) (1966), 1295-1309.

27. Khachaturyan, A. G., Semenovskaya, S. V. and Morris, J. W., "Theoretical Analysis of Strain-Induced Shape Changes in Cubic Precipitates during Coarsening," Acta Metall., 36 (6) (1988), 1563-1572.

28. Reed, R. C., Yeh, A. C., Tin, S., Babu, S. S. and Miller, M. K., "Identification of the Partitioning Characteristics of Ruthenium in Single Crystal Superalloys Using Atom Probe Tomography," Scripta Mater., 51 (4) (2004), 327-331.

29. Jayaram, R., Hren, J. J. and Miller, M. K., “APFIM/TEM characterization of solute partitioning in a model nickelmolybdenum-aluminum-tantalum superalloy," Surf. Sci., 246 (13) (1991), 323-328.

30. Blavette, D. and Bostel, A., "Phase Composition and LongRange Order in $\gamma^{\prime}$ Phase of a Nickel-base Single Crystal Superalloy CMSX2: An Atom Probe Study," Acta Metall., 32 (5) (1984), 811-816.

31. Jia, C. C., Ishida, K. and Nishizawa, T., "Partition of alloying elements between $\gamma$ (A1), $\gamma^{\prime}$ (L12), and $\beta$ (B2) phases in Ni-Al base systems" Metall. Mater. Trans., A, 25 (3) (1994), 473-485.

32. Miller, M. K., Jayaram, R., Lin, L. S. and Cetel, A. D., "APFIM Characterization of Single-Crystal PWA 1480 Nickelbase Superalloy,” Appl. Surf. Sci., 76-77 (1-4) (1994), 172-176.

33. More, K. L. and Miller, M. K., "Microstructural Characterization of Udimet 720: A nickel-base Alloy," J. Phys. C6 49 Supp. 11, (1988), 391-396.

34. Ochiai, S., Oya, Y. and Suzuki, T., "Alloying Behavior of Nickel-Aluminum, Nickel-Gallium, Nickel-Silicon, and NickelGermanium $\left(\mathrm{Ni}_{3} \mathrm{Al}, \mathrm{Ni}_{3} \mathrm{Ga}, \mathrm{Ni}_{3} \mathrm{Si}\right.$ and $\left.\mathrm{Ni}_{3} \mathrm{Ge}\right)$," Acta Metall., 32 (2) (1984), 289-298.

35. Karg, A. V., Fornwalt, D. E. and Kriege, O. H., "Effect of Alloying Elements on the Intensity of Superlattice Reflections of $\mathrm{Ni}_{3} \mathrm{Al}$," J. Inst. Metals, 99 (Oct.) (1971), 301-305.

36. Saito, Y. and Harada, H., "The Monte Carlo Simulation of Ordering Kinetics in Ni-base Superalloys," Mater. Sci. Eng., A, A223 (1-2) (1997), 1-9.

37. Ruban, A. V. and Skriver, H. L., "Calculated Site Substitution in Ternary $\gamma^{\prime}-\mathrm{Ni}_{3} \mathrm{Al}$ : Temperature and Composition effects," Phys. Rev. B, 55 (2) (1997), 856-874.
38. Wang, S.-Y., Wang, C.-Y., Sun, J.-H., Duan, W.-H. and Zhao, D.-L., "Energetics and Electronic Structure of Re and Ta in the $\gamma^{\prime}$ phase of Ni-based Superalloys," Phys. Rev. B, 65 (3) (2002), 035101/035101-035101/035107.

39. Sluiter, M. H. F. and Kawazoe, Y., "Site Preference of Ternary Additions in $\mathrm{Ni}_{3} \mathrm{Al}$," Phys. Rev. B, 51 (7) (1995), 40624073.

40. Raju, S., Mohandas, E. and Raghunathan, V. S., "A Study of Ternary Element Site Substitution in $\mathrm{Ni}_{3} \mathrm{Al}$ using Pseudopotential Orbital Radii Based Structure Maps," Scripta Mater., 34 (11) (1996), 1785-1790.

41. Murakami, H., Harada, H. and Bhadeshia, H. K. D. H., "The Location of Atoms in Re- and V-Containing Multicomponent Nickel-base Single-Crystal Superalloys," Appl. Surf. Sci., 76-77 (1-4) (1994), 177-183.

42. Murakami, H., Koizumi, Y., Yokokawa, T., Yamabe-Mitarai, Y., Yamagata, T. and Harada, H., "Atom Probe Microanalysis of Ir-bearing Ni-based Superalloys," Mater. Sci. Eng., A, A250 (1) (1998), 109-114.

43. Enomoto, M. and Harada, H., "Analysis of $\gamma^{\prime} / \gamma$ Equilibrium in Nickel-Aluminum-X Alloys by the Cluster Variation Method with the Lennard-Jones Potential," Metall. Trans. A, 20A (4) (1989), 649-664.

44. Wu, Y. P., Tso, N. C., Sanchez, J. M. and Tien, J. K., "Modeling of Ternary Site Occupation in $\mathrm{L}_{2}$ Ordered Intermetallics," Acta Metall., 37 (10) (1989), 2835-2840.

45. Machlin, E. S. and Shao, J., "Quaternary Gamma-Prime ( $\left.\mathrm{L}_{2}\right)$ Pseudobinary Properties as Revealed by the Ionicity Modified Pair Potential Model," Scripta Metall., 11 (10) (1977), 859-862.

46. Guard, R. W. and Westbrook, J. H., "Alloying Behavior of $\mathrm{Ni}_{3} \mathrm{Al}$ ( $\gamma^{\prime}$-phase),” AIME Trans., 215 (1959), 807-814.

47. Lin, H., Seiberling, L. E., Lyman, P. F. and Pope, D. P., "Lattice Location of Tantalum in Nickel-Aluminum $\left(\mathrm{Ni}_{3} \mathrm{Al}\right)$ by Ion Channeling and Nuclear Reaction Analysis," Proc. MRS Symp., 81 (High-Temp. Ordered Intermet. Alloys 2) (1987), 165170.

48. Mekhrabov, A. O., Akdeniz, M. V. and Arer, M. M., “Atomic Ordering Characteristics of $\mathrm{Ni}_{3} \mathrm{Al}$ Intermetallics with Substitutional Ternary Additions," Acta Mat., 45 (3) (1997), 1077-1083.

49. Arbuzov, M. P., Kachkovskaya, E. T. and Khaenko, B. V., "X-ray Diffraction Study of the Structure of $\mathrm{Ni}_{3} \mathrm{Al}$, Alloyed with Ti, Cr, and W," Fiz. Metall. Metallovd., 21 (6) (1966), 854-857. 